Dermatologische Zeitschrift. 1895;2:530-531

\title{
Praktische Notizen
}

Dr. A. Heidenhain in Steglitz hat einen praktischen Leder-Stempel construiert, um auf schonende Weise Salben einzureiben. Dieser „Inunctor” besteht aus einem polierten Holzgriíf handlicher Form, an dessen peripnerem Ende ein elastisches Kugelsegment aus Leim und Gummi angebracht und mit un-

$-531-$

gefärbtem Wasehleder überzogen ist. Das Leder kann beliebig erncucrt werden. Gegenüber den übliclien Borstenpinseln ist das kleine Instrument ein Fortschritt. Das Verfahren damit ist prompt und reinlich. Die Firma Max Kaehler \& Martini, Berlin W., Wilheliustrasse 50, stellt dasselb $\theta$ in alien gewiinschten GrOssen her.

Die elektrische Epilation bei Hypertrichosis begegnet schon aus äusseren Gründen mancherlei Schwierigkeit. Hierzu gehört der grosse Zeitaufwand und die damit verbundenen Opfer. Da nun aber die Mehrzahl der in Betracht kommenden Persünlichkeiten dem reiferen Miidcbenstande in abliängiger \&gt; Stellung anzugehören pflegt und unmöglich laugdauernde Curen durchmaclien kann, so lag der Gedanke nahe, ihnen auf andere Weise zu helfen: In einigen Sitzungen lernen sie leicht die Epilation selber an sich auszuüben und können dann das langwierige Verfahren unauffällig und in aller Stille zu Ende fiihren. Die hierí'iir erforderliche schwache galvanische Stromquelle ist in Form einer kleinen, portativen Chromsäure-Tauchbatterie (wie sie z. B. G. Behrend in der II. Auflage der Eulenburg'schen Realencyclopüdie angegeben hat) leicht zu beschaffen. Auf meinen Wunsch halt jetzt A. W. Hirschmann, Berlin 2Ñ., Johannisstrasse, solche Batterieen mit allem Zubehör zu mässigem Preise auf Lager. Die Clientinnen werden in der Ausübung der Manipulation ausreichend unterwiesen und epilieren dann selbst weiter. So wird das sonst in den meisten praktischen Fallen schwer erreiohbare Ziel angebahnt und einer ganzen Anzahl von Leidenden zur allmähligen Beseitigung eines Uebelstandes verholfen, welcher sonst schwer auf ihrer Unbefangenheit zu lasten ptiegt. Lassar. 